\title{
Linear Electric Motors in Machining Processes
}

\author{
Jacek F. Gieras *
}

\begin{abstract}
Application of linear electric motors to automation of manufacturing processes, gantry robots, machining processes, machining centers, additive manufacturing and laser scribing has been discussed. The paper focuses on replacement of ball lead screw mechanisms with linear electric motors, linear motor driven positioning stages, linear motor driven gantries, machining centers, machining of large objects and industrial lasers. The best linear electric motors for application to machining processes are permanent magnet (PM) linear synchronous motors (LSMs), especially those without PMs in the reaction tail, e.g., high thrust density linear (HDL) LSMs and PM flux switching (FS) LSMs.
\end{abstract}

Keywords: Linear motors, Synchronous motors, Permanent magnet motors, Manufacturing processes, Machining centers, Ball lead screw mechanisms, Positioning stages, Gantries, Machining of large parts, Industrial lasers.

\section{Introduction}

Machining processes are a part of manufacturing production [10]. Machining can be defined as the process of removing material from a workpiece in the form of chips using labor and machine tools. It covers several processes, which can be divided into the following categories: (a) cutting, generally involving single-point or multipoint cutting tools, (b) abrasive processes, such as grinding and (c) nontraditional machining, utilizing electrical, chemical, and optimal sources of energy. Machining, as any other manufacturing operation, can be viewed as a system consisting of the workpiece, the tool and the machine.

Manufacturing process automation frees the human operator from control functions, i.e., need to perform certain actions in a particular sequence to carry out an operation in accord with preset machining conditions [3].

Automation is the use of the energy of a nonliving system to control and carry out a process or process operation without direct human intervention $[3,36]$. The object of automation is to make the best use of available resources, materials, and machines. The human worker's function is limited to machine supervisory control and elimination of possible deviations from the prescribed process (corrective adjustment).

In automatic systems, actuation components are adapted to moving various mechanisms of machine tools to execute the required step of control, e.g., change the mode of operation, release a workpiece, start or stop the machine, etc. One of the emerging technologies is the use of linear electric motors as electromagnetic actuators.

Dept. of Electrical Engineering, University of Technology and Life

Sciences, Bydgoszcz, Poland; and Applied Research, UTC

Aerospace Systems, Rockford, IL, USA (jgieras@ieee.org)

Received 15 August 2013; Accepted 5 October 2013

\section{Ball Lead Screws}

\subsection{Ball Lead Screw Drives}

Normally, the rotation of a rotary servo motor, usually PM brushless motor, is converted into linear motion in $x, y, z$, or $w$ (e.g., tool) direction with the aid of ball lead screws. The force balance equation of a linear drive system can be described by the following equation

$$
m \frac{d^{2} x}{d t^{2}}+D_{v} \frac{d x}{d t}+k_{s} x+F_{e x t}(t)=F_{d x}(t)
$$

where $\mathrm{m}$ is the total mass of the load including the table (thrust block), Dv is the viscous friction (damping) constant of the load, ks is the spring constant, Fdx is electromagnetic force produced by the motor, Fext represent all external (disturbance) forces acting on the system, and $\mathrm{x}$ is the linear displacement of the load.

The position displacement, velocity, and acceleration of a linear drive can be expressed as

$$
\begin{gathered}
x(t)=X_{m} \sin (\omega t) \\
\dot{x}(t)=\frac{d x(t)}{d t}=\omega X_{m} \cos (\omega t) \\
\ddot{x}(t)=\frac{d^{2} x(t)}{d t^{2}}=-\omega^{2} X_{m} \sin (\omega t) \\
F_{e x t}(t)=m \omega^{2} X_{m} \sin (\omega t)+D_{v} \omega^{2} X_{m} \sin (\omega t)
\end{gathered}
$$


where $X_{m}$ is the maximum position error. Assuming in eqn (1) $F_{d x}=0$ (uncontrolled system) and $k_{s}=0$, the external (disturbance) force is (5).

Neglecting the viscous friction constant $(\mathrm{Dv} \approx 0)$, the external force becomes

$$
F_{e x t}(t) \approx m \omega^{2} X_{m} \sin (\omega t)
$$

The static stiffness of a linear drive system is defined as the external force-to-position displacement ratio, i.e.,

$$
K_{s}=\frac{F_{e x t}}{x} \quad \frac{\mathrm{N}}{\mathrm{m}}
$$

The dynamic stiffness of a linear drive system is defined as the external force-to-system response ratio, i.e.,

$$
K_{d}=\frac{F_{e x t}(t)}{x(t)} \approx m \omega^{2} \quad \frac{\mathrm{N}}{\mathrm{m}}
$$

since $\mathrm{x}$ is the position displacement and $\operatorname{Fext}(\mathrm{t})$ is givewn by (6). Low dynamic stiffness Kd leads to poor disturbance rejection and sensitivity to load variation [28].

In general, a high static and dynamic stiffness can be achieved by raising the controller gains [22,30].

For a ball screw system with rotary motor and tooth gear driving a table (Fig. 1)

$$
\begin{gathered}
m_{t} \ddot{x}+\left(\frac{2 \pi}{\tau_{l}}\right)^{2}\left[J_{b s}\left(\frac{N_{2}}{N_{1}}\right)^{2} J_{m}\right] \ddot{x}=\frac{2 \pi}{\tau_{l}}\left[\frac{N_{2}}{N_{1}}\left(T_{d}-D_{v m} \dot{\Theta}-T_{e x t m}\right)\right] \\
-\frac{2 \pi}{\tau_{l}}\left(D_{v b s} \dot{\Theta}_{b s}+T_{e x t b s}\right)-D_{v t} \dot{x}-F_{e x t}
\end{gathered}
$$

where $m_{t}$ is the mass of the moving table; $\tau_{l}$ is the screw pitch (axial distance between two adjacent threads); $J_{b s}$ and $\boldsymbol{J}_{m}$ are moments of inertia of the ball screw and motor respectively; $N_{l}$ and $N_{2}$ are the numbers of teeth on the motor and ball screw gears, respectively; $D_{v t}, D_{v m}, D_{v b s}$ are viscous friction coefficients of the table, motor and ball screw, respectively; $F_{\text {ext }}$ is the external (disturbance) force on the table; $T_{d}$ is the torque developed by the motor; $T_{\text {extm }}$ and $T_{\text {extbs }}$ are external torques acting on the motor shaft and ball screw, respectively; $x$ is the linear displacement of the load; and $\Theta_{m}, \Theta_{b s}$ are angular displacements of the motor and ball screw, respectively.

Assuming $T_{d}=0, D_{v m}=0, D_{v b s}=0, D_{v t}=0$, $T_{\text {extm }}=0, T_{\text {extbs }}=0$ and denoting

$$
J_{e}=J_{b s}+\left(\frac{N_{2}}{N_{1}}\right)^{2} J_{m} .
$$

where $J_{e}$ is the equivalent moment of inertia of the ball screw and motor, the external (disturbance) force of a ball screw system obtained from (9) is

$$
F_{e x t} \approx\left[m_{t}+\left(\frac{2 \pi}{\tau_{l}}\right)^{2} J_{e}\right] \omega^{2} X_{m} \sin (\omega t)
$$

and dynamic stiffness

$$
K_{d} \approx\left[m_{t}+\left(\frac{2 \pi}{\tau_{l}}\right) J_{e}\right] \omega^{2}
$$

(a)

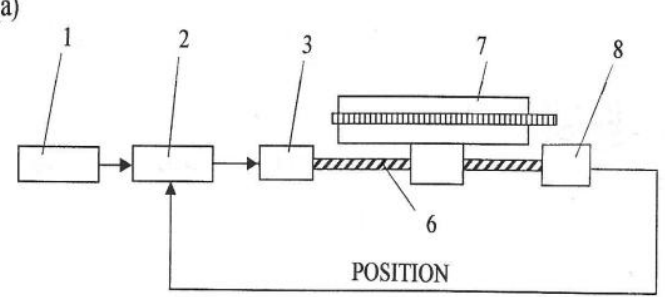

(b)

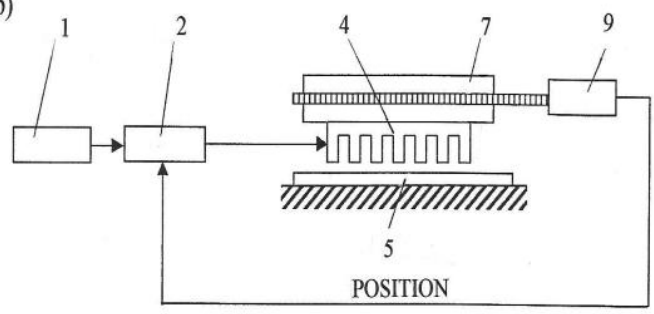

Fig. 1. Axis drive system with (a) ball lead screw, (b) linear motor. 1. interpolator, 2. controller, 3. low inertia servomotor, 4. armature of a linear motor, 5. reaction rail of a linear motor, 6 . ball lead screw, 7 . table (guide), 8. rotary encoder or resolver, 9. linear sensor.

The force provided by a ball screw

$$
F_{b s}=\frac{\eta_{b}}{t_{r}} T_{b s}=\frac{2 \pi \eta_{b}}{l} T_{b s}
$$

where $\eta_{b}=\left(T_{b s}-T_{f}\right) T_{b s}$ is the efficiency of the ball screw, $\boldsymbol{t}_{r}=1 /(2 \pi)$ is the transmission parameter (axial distance moved per one radian of screw revolution), $l=k \tau_{l}$ is the lead (helix) of the screw (axial distance moved by the nut in one revolution of the screw), $k$ is the number of independent threads, $T_{b s}$ is the torque provided by the screw, and $T_{f}$ is the torque to overcome the frictional force. The acceleration can be found from (4) and (11) Maximum acceleration $a_{\text {max }}$ is for maximum torque $T_{b s}$.

In [22] the static servo stiffness of the ball screw feed drive system is expressed as 


$$
K_{s}=a_{b} K_{p} K_{v} T_{\max }\left(1+b_{b} K_{i}\right)\left(\frac{2 \pi}{l}\right)^{2}
$$

where $\mathrm{Kp}$ is the proportional gain, $\mathrm{Ki}$ is the integral gain, $\mathrm{Kv}$ is the position loop gain, Tmax is the peak torque of the servo motor, $a b$ and $b b$ are constant parameters. For example, conventional machining centers use ball screws with the pitch $\tau \mathrm{l}=10$ to $14 \mathrm{~mm}$ and servo motors with maximum speeds $\operatorname{nmax}=2000$ to $2500 \mathrm{rpm}$ which gives maximum linear speed $\operatorname{vmax}=20$ to $30 \mathrm{~m} / \mathrm{min}$, acceleration $\operatorname{amax}=0.2 \mathrm{~g}$ to $0.3 \mathrm{~g}$ and $\mathrm{Ks} \approx 23 \times 108$ [22].

\subsection{Replacement of Ball Screws with LSMs}

Linear motors can successfully replace ball lead screws. Fig. 1 shows two methods of obtaining high linear speed (feed rate) and high acceleration by using a ball lead screw and linear motor. Rotary servo motors can use either a rotary encoder or linear encoder with table-mounted scale, while linear motors use only linear encoders.

The tubular linear synchronous motor (LSM) with $\mathrm{NdFeB}$ permanent magnets (PMs) in the thrust rod (reaction rail) offers an attractive alternative to ball screw solutions. Comparison of tubular LSMs with ball screws is given in Table I.

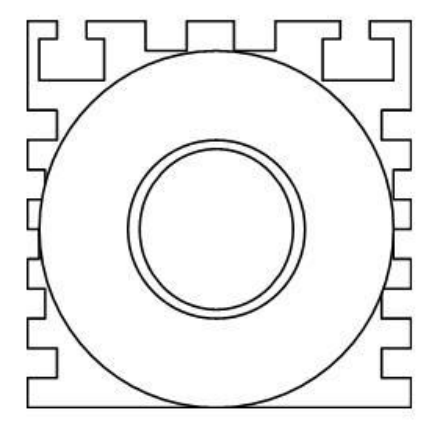

Fig. 2. Extruded heat sink - housing of tubular LSM.

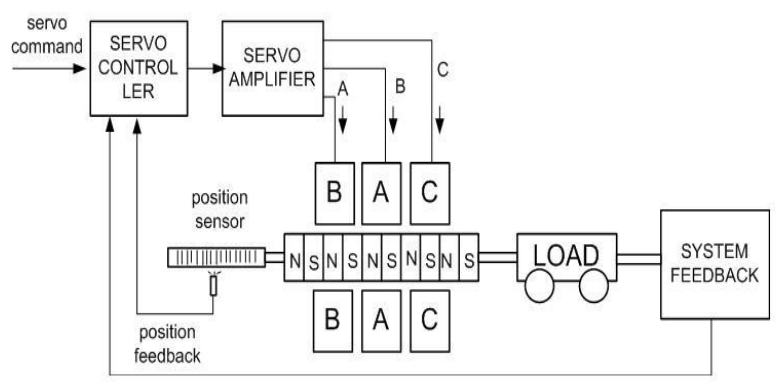

Fig. 3. Motion control system with tubular LSM.

Sustainable thrust developed by a tubular LSM is a function of the motor ability to dissipate heat. Maximum force and velocity are controlled by the choice of the winding current density and cooling option (heat sink, forced air, water jacket). An extruded housing (Fig. 2) can serve as an armature (forcer) heat sink and increase the continuous thrust by a factor of 1.15 . Modern tubular LSMs can deliver thrust density (thrust per mass) up to 500 $\mathrm{N} / \mathrm{kg}$. Thrust rod masses for $25 \mathrm{~mm}$ diameter rods are typically $3.5 \mathrm{~kg} / \mathrm{m}$. Examples of motion-control systems with tubular LSMs are shown in Figs 3 and 4 (two-axis positioning stage).

Table 1. Comparison of tubular LSMs with ball screws.

\begin{tabular}{|c|c|c|}
\hline Performance & Tubular LSMs & $\begin{array}{c}\text { Ball screws and } \\
\text { roller screw linear } \\
\text { actuators with } \\
\text { rotary motors }\end{array}$ \\
\hline $\begin{array}{c}\text { Thrust density, } \\
\mathrm{N} / \mathrm{kg}\end{array}$ & max. 500 & over 1200 \\
\hline Speed, m/s & 2.5 & 0.25 \\
\hline $\begin{array}{c}\text { Position accuracy, } \\
\text { mm }\end{array}$ & \pm 0.025 & \pm 0.025 \\
\hline $\begin{array}{c}\text { Stiffness ability to } \\
\text { hold a position }\end{array}$ & high & high \\
\hline $\begin{array}{c}\text { Controllability } \\
\text { zero backlash }\end{array}$ & $\begin{array}{c}\text { Fucklash increases } \\
\text { with time }\end{array}$ \\
\hline $\begin{array}{c}\text { Life-cycle cost } \\
\text { parts }\end{array}$ & $\begin{array}{c}\text { very low; } 2 \text { wearing } \\
\text { moderate; to } 4 \text { to } \\
200 \text { wearing parts }\end{array}$ \\
\hline Temperature, ${ }^{0} \mathrm{C}$ & none & $\leq 125$ \\
\hline $\begin{array}{c}\text { Environmental } \\
\text { impact }\end{array}$ & 40 & minimal \\
\hline Noise level, dB & $\begin{array}{c}\text { More expensive than } \\
\text { ball screw and roller } \\
\text { screw actuators due } \\
\text { to limited demand }\end{array}$ & Moderate \\
\hline Cost & & \\
\hline
\end{tabular}

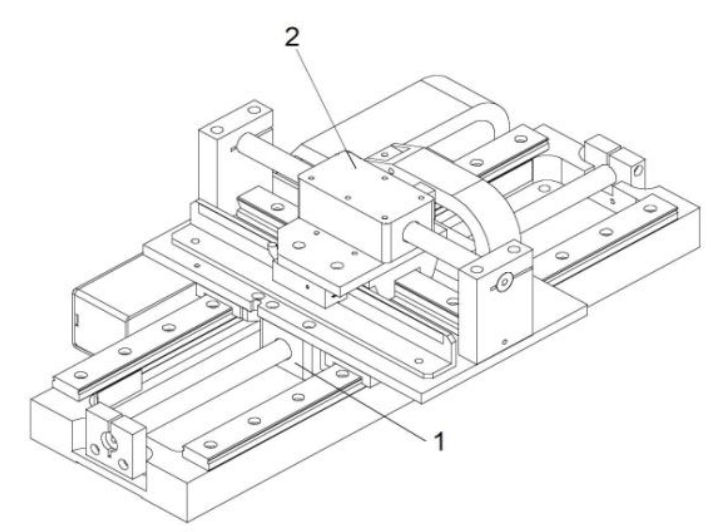

Fig. 4. Two-axis linear positioning stage as an example of replacement ball lead screw mechanisms with tubular LSMs. $1-x$-direction tubular LSM, $2-y$ direction tubular LSM [25].

Although tubular PM LSM in comparison with ball screw PM brushless motor linear actuators develop 10 times higher linear speed, provide fully programmable, zero backlash controllability and emit much lower noise, the maximum force density is only $500 \mathrm{~N} / \mathrm{kg}$ versus over 1200 $\mathrm{N} / \mathrm{kg}$ from linear actuators with rotary PM brushless motors (Table 1). 


\section{Linear Positioning Stages}

Every motorized positioning stage considered as an electromechanical system comprises three essential components: (1) stage, (2) motor, and (3) controller. Positioning stages have travel range from a few micrometers to several meters.

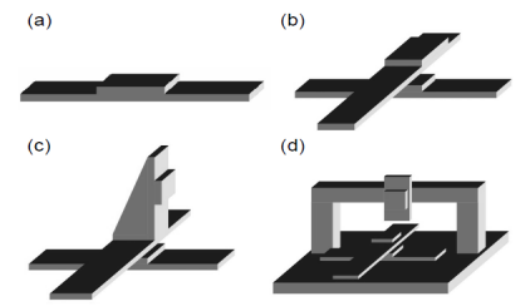

Fig. 5. Configurations of linear positioning stages: (a) single axis, (b) compound $x y$, (c) compound $x y z$, (d) split $x y z$ [25].

Configurations of positioning stages are shown in Fig. 5 [25]. The simplest form of positioning stage is a singleaxis stage (Fig 5a). It typically consists of a moving table (carriage), base, motor, encoder, limit switches and cable carriers. A compound $x y$ positioning stage (Fig. 5b) provides the simplest form of 2 linear degrees of freedom (DOF) of a positioning system where the base of the top axis is bolted to the moving table of the lower axis [25]. A compound $x y z$ stage (Fig. 5c) provides the simplest form of 3 linear DOF of a positioning system with the smallest footprint. A split xyz positioning stage (Fig. 5d) provides typically higher precision and higher stiffness than a compound configuration of the same number of axes [25].

Positioning stages with linear motors are far simpler to design and assemble compared to a stage that is based on a rotary motor. The ball screw, coupling, gears, rack-andpinion, or belts are all eliminated.

The single-axis positioning stage shown in Fig. 5a can be driven by a three-phase, double-sided PM LSM with ironless core, commutated either sinusoidally or trapezoidally $[25,31,38]$. The ironless armature assembly has no electromagnetic attractive force to the stationary PM assembly, which reduces the load on, and increases the life of, the bearing system. The encapsulated armature coil assembly moves, and the multipole PM assembly is stationary. The lightweight coil assembly allows for higher acceleration of light payloads than heavier PM assembly. Linear guidance is achieved by using a single linear rail with one or two linear recirculating ball-bearing guides. The bearing is sealed with wipers to contain the lubrication and to keep out debris.

A linear precision positioning stage with two tubular LSMs to obtain the $x-y$ motion is shown in Fig. 4. Multiaxis linear positioning stages provide a very compact platform for accurate positioning of delicate payloads in high-cycle applications.

When neglecting the electrical dynamics of the LSM and assuming

$$
F_{e x t}=F_{r}+F_{e x t m}
$$

the dynamics of a single-axis positioning stage can be described by the following equation

$$
m \frac{d^{2} x}{d t^{2}}+D_{v} \frac{d x}{d t}+k_{s} x+F_{r}+F_{e x t m}=k_{F} I_{a}
$$

where $m$ is the mass of the moving table, $D_{v}$ is the damping/friction constant; $k_{s}$ is the spring constant; $F_{r}$ is the external disturbance force, e.g., ripple force, $F_{\text {extm }}$ is the external force during manufacturing operation; $\mathrm{k}_{\mathrm{F}}$ is the thrust constant (Newton/A); $I_{a}$ is the armature current and $F_{d x}=k_{F} I_{a}$. Compare (16) with (1).

Controllers are units that interface the user with the linear positioning stage. They have computer interfaces and interfaces to the linear motor of the stage. The controller can also be remotely operated. The controller has inputs for encoders of the stage. Most controllers are also programmable by downloading an instruction set onto them. A common programming platform for many controllers is ActiveX, which is user friendly. ActiveX is a losely defined set of technologies developed by Microsoft for sharing information among different applications.

\section{Gantry Robots}

The term "gantry" defines a system with two motors controlling a single linear axis. Each motor/bearing system is separated a finite distance orthogonal to the direction of the axis. The most common mechanical systems use either linear motors or rotary motors with ballscrews (or belts). A typical gantry configuration is shown in Fig. 6.

A gantry robot consists of a manipulator mounted onto an overhead system that allows movement across a horizontal plane. Each of the motions is arranged to be perpendicular to the other, and are typically labeled $x, y$, and $z$. Motions in the $\mathrm{x}$ and $\mathrm{y}$ directions are located in the horizontal plane, while $z$ is the vertical direction. Specifications in the $x$ and $y$-axis require an absolute position accuracy of less than $\pm 0.05 \mathrm{~mm}$ for manufacturing processes and less than $\pm 5.0 \mathrm{~mm}$ for factory transportation systems.

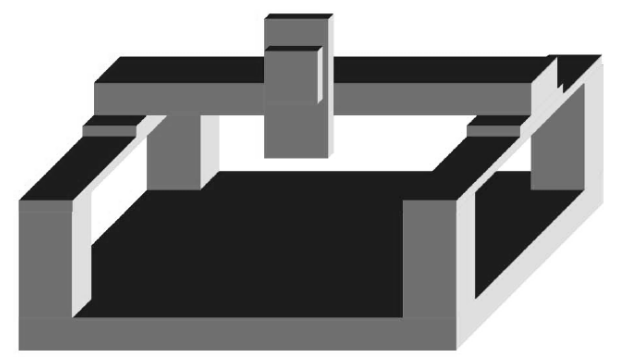

Fig. 6. Gantry configuration. 
Gantry robot systems with PM LSMs provide the following advantages:

- large work envelopes (not restricted by arm length),

- less limited by floor space constrains than other robots,

- better suited for multiple machines and conveyor lines,

- better handling of large or awkward payloads,

- very good positioning accuracy

- better acceleration,

- improved efficiency and versatility,

- easy programming with respect to motion, because gantry robots work with $x y z$ coordinate system,

- superiority of optimum schedule

The Hercules family of gantries (Anorad, Shirley, NY, USA) are designed to address a multitude of performance requirements for inspection, pick-and-place, assembly, or dispensing applications. The Hercules gantry stages are based on a single platform design, where many linear servo motor selections, linear encoder options, and several travel lengths allow for uniquely supporting a variety of applications with a cost-effective solution. The standard model Hercules gantries feature high force produced by ironcored LSMs combined with a low mass $x$-axis crossbeam, and high acceleration to maximize throughput.

Aerotech, Pittsburgh, PA, USA has introduced the AGS20000 gantries with LSMs, which are believed to bethe most powerful and accurate Cartesian gantries in the world [1]. Dual PM linear brushless servomotors and dual linear encoders offer high linear velocity up to $3 \mathrm{~m} / \mathrm{s}$, high acceleration up to $5 \mathrm{~g}$, accuracy $\pm 3.0 \mathrm{~mm}$, and resolution 0.02 to $1.0 \mathrm{~mm}[1]$

\section{Machining Processes}

The seven basic machining processes are shaping, drilling, turning, milling, sawing, broaching, and abrasive machining. To accomplish the basic machining processes, eight basic types of cutting machine tools have been developed [10]:

- shapers and planers,

- drill presses,

- lathes,

- boring machines,

- milling machines,

- saws,

- broaches,

- grinders.

For example, constructions of milling machines are shown in Fig. 7.

\subsection{Machining Centers}

A machining center is a specifically designed and computer numerically controlled (CNC) single machine tool with a single workpiece set up to permit several of the basic processes, plus other related processes [10]. Thus, a machining center can perform a variety of processes and change tools automatically while under programmable control. Numerical control is a method of controlling the motion of machine components by means of coded instructions generated by microprocessors or computers.
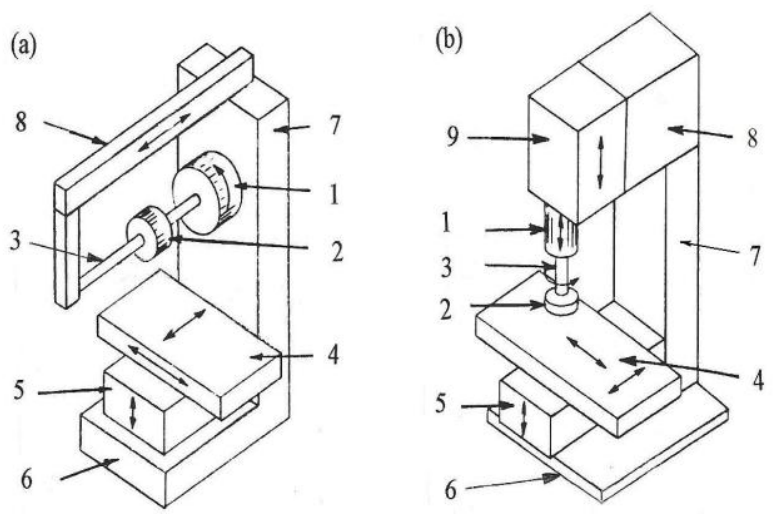

Fig. 7. Major components of knee type milling machines with (a) horizontal spindle, (b) vertical spindle. 1. spindle, 2. cutter, 3. arbor, 4. table, 5. knee, 6. base, 7 . column, 8 . overarm, 9 . head.

A part to be machined is fixed to the $x-y$ table of the machining center, which must provide a movement both in the $x$ and $y$ directions (Fig. 8). The vertical $\mathrm{z}$ movement is provided by the head, e.g., to control the depth of drilled holes. This can also be achieved by moving the cutting tool in the $w$ direction (Fig. 8). To obtain the full flexibility of machining, the vertical cutting tool should rotate around its horizontal axis ( $\alpha$ direction). Closed-loop position control is used in each of five axes.

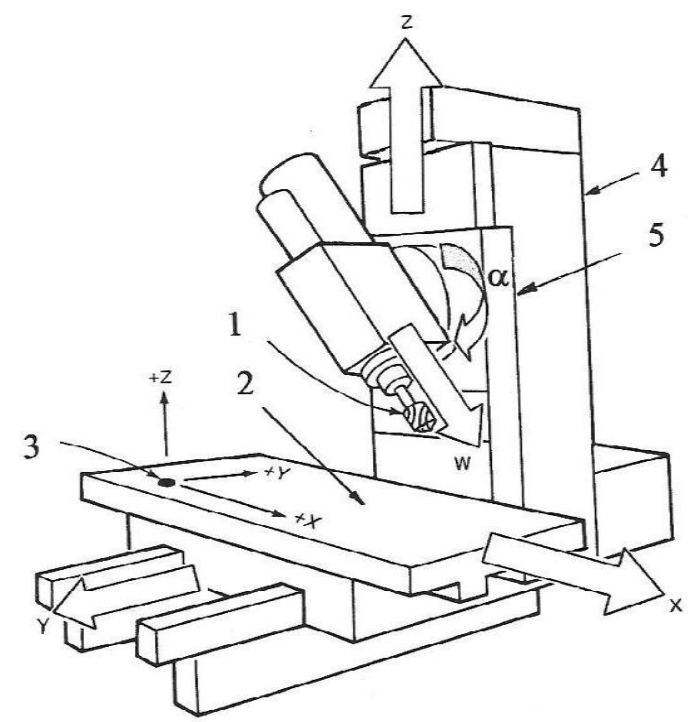

Fig. 8. Five-axis vertical spindle machining center. 1. cutting tool, 2. table, 3. machine zero point, 4. column, 5. head. 


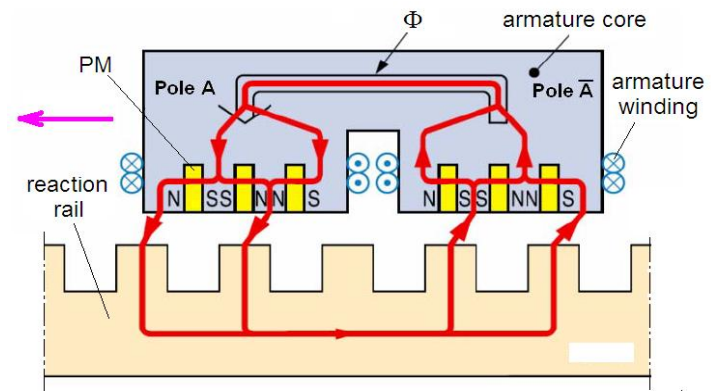

Fig. 9. HDL PM LSM developed by Shinko Electric Co. Ltd (now Shinko Sinfonia), Takegahama Ise, Japan.

High-speed modern machining centers were developed in the early 1990s (Makino Milling Company and Comau Company) [22]. Specifications of high-speed machining centers are given in Table 2. The maximum speed $v_{\max }=60 \mathrm{~m} / \mathrm{min}$ is at least twice higher, and the maximum acceleration $a_{\max } \approx 1 \mathrm{~g}$ is at least three times higher than those of conventional machining centers. On the other hand, the static servo stiffness (7) of high speed machining centers decreases about 18 times in comparison with conventional machining centers, which is a disadvantage.

Table 2. Specifications of a modern high speed machining centers with ball lead screws [22].

\begin{tabular}{|c|c|c|c|}
\hline Parameter & $x$-axis & $y$-axis & z-axis \\
\hline Stroke, $\mathrm{m}$ & 0.56 & 0.41 & 0.41 \\
\hline $\begin{array}{l}\text { Maximum linear speed } \\
\text { (feed rate), } \mathrm{m} / \mathrm{min}\end{array}$ & \multicolumn{3}{|c|}{60} \\
\hline Maximum acceleration & $1.0 \mathrm{~g}$ & $1.2 \mathrm{~g}$ & $0.9 g$ \\
\hline Mass of slider, $\mathrm{kg}$ & 235 & 500 & 425 \\
\hline $\begin{array}{l}\text { Ball lead screw } \\
\text { - Diameter, mm } \\
\text { - Pitch } \tau_{l}, \mathrm{~mm} \\
\text { - Type of support }\end{array}$ & \multicolumn{3}{|c|}{$\begin{array}{c}36 \\
20 \\
\text { Single }\end{array}$} \\
\hline Type of guideway & \multicolumn{3}{|c|}{ Sliding } \\
\hline Control & \multicolumn{3}{|c|}{ Semi-closed loop } \\
\hline Positioning resolution, $\mathrm{mm}$ & \multicolumn{3}{|c|}{0.001} \\
\hline $\begin{array}{c}\text { Spindle } \\
\text { - Diameter, mm } \\
\text { - Rated output power, } \mathrm{kW} \\
\text { - Rotational speed, rpm }\end{array}$ & \multicolumn{3}{|c|}{$\begin{array}{c}65 \\
30 \\
20,000\end{array}$} \\
\hline
\end{tabular}

Linear induction motors (LIMs) [13] are not recommended motors for machine tool applications because they have low efficiency and power factor and emit large amounts of heat. PM LSMs or PM linear brushless motors (LBMs) are much better motors because they are smaller and can provide efficiency over $75 \%$, high power factor, and fast response. According to Shinko Electric Co. Ltd, Takegahana Ise, Japan, the so-called PM high-thrust density linear motor (HDL) has efficiency over 90\% at low speed and very high acceleration [23], [28]. An HDL is similar to a hybrid linear stepping motor (HLSM), i.e., both have forcer windings and toothed reaction rail. However, the HDL has a different arrangement of PMs (Fig. 9). Table
3 compares the performance of three different linear motors, i.e., LIM, LSM and HDL for applications to machine tools [22], [28]. The HDL is sometimes called flux-reversal PM LSM [7].

The most important variable that describes the behavior of a position control loop for computer numerically controlled (CNC) machine tool driven by a linear motor servo drive is position loop gain $K_{v}$ [30], which is the ratio of the command velocity (feed rate) $v$ to the position control deviation (following error, tracking error, lag) $\Delta x$, i.e.,

$$
K_{v}=\frac{v}{\Delta x} \quad \frac{1}{s}
$$

In general, the position loop gain $K_{v}$ should be high for faster system response and higher accuracy, but the maximum gains allowable are limited due to undesirable oscillatory responses at high gains and low damping factor [30].

Table 3. Comparison of linear motors for machine tools.

\begin{tabular}{|c|c|c|c|}
\hline Parameter & LIM & LSM & HDL \\
\hline $\begin{array}{c}\text { Dimensions } \mathrm{L} \times \\
\mathrm{W} \times \mathrm{H}, \mathrm{mm}\end{array}$ & $222 \times 50 \times 49.5$ & $160 \times 50 \times 27$ & $290 \times 79 \times 40$ \\
\hline $\begin{array}{c}\text { Mass of } \\
\text { armature, } \mathrm{kg}\end{array}$ & 4.29 & 1.89 & 6.47 \\
\hline Air gap, mm & 1.0 & 0.5 & 0.2 \\
\hline $\begin{array}{l}\text { Resistance per } \\
\text { phase, } \Omega\end{array}$ & 1.72 & 26.8 & 0.193 \\
\hline $\begin{array}{c}\text { Inductance per } \\
\text { phase, } \mathrm{mH}\end{array}$ & 14.4 & 54.7 & 5.62 \\
\hline Pole pitch, mm & 54 & 33 & 10 \\
\hline $\begin{array}{l}\text { Construction of } \\
\text { armature }\end{array}$ & Winding & Winding & $\begin{array}{c}\text { Winding + } \\
\text { PMs }\end{array}$ \\
\hline $\begin{array}{l}\text { Construction of } \\
\text { reaction rail }\end{array}$ & $\mathrm{Cu}+\mathrm{Fe}$ & $\mathrm{PMs}+\mathrm{Fe}$ & $\mathrm{Fe}$ \\
\hline $\begin{array}{l}\text { Cogging (detent) } \\
\text { force }\end{array}$ & None & Exists & Exists \\
\hline Rated current, A & 4.0 & 1.03 & 16.9 \\
\hline Rated thrust, N & 48 & 139 & 880 \\
\hline $\begin{array}{c}\text { Thrust constant } \\
k_{F}, \text { N/A }\end{array}$ & 12 & 135 & 52 \\
\hline $\begin{array}{c}\text { Maximum } \\
\text { efficiency, \% }\end{array}$ & 18 & 77 & 92 \\
\hline $\begin{array}{c}\text { Efficiency at } \\
\text { rated thrust and } \\
v=1 \mathrm{~m} / \mathrm{s}, \%\end{array}$ & 12.5 & 60 & 62 \\
\hline $\begin{array}{c}\text { Thermal } \\
\text { resistance, }{ }^{\circ} \mathrm{C} / \mathrm{W}\end{array}$ & 0.87 & 0.686 & 0.291 \\
\hline
\end{tabular}

Usually, the $K_{v}$ factor is experimentally tuned on the already assembled machine tool or can be calculated with the aid of the following equation [30]:

$$
K_{v}=\frac{1}{4 \varsigma^{2}\left(\frac{2 D}{\omega}+\frac{T_{s}}{2}\right)} \frac{1}{\mathrm{~s}}
$$


where $\omega$ is the angular frequency, $D$ is the dimensionless damping constant (different than $D_{v}$ in eqns (1) and (16)), $\zeta$ is the position control loop damping $(0<\zeta<1)$, and $T_{S}$ is the sampling period. In practice, the $K_{v}$ must be reduced up to $60 \%$ of that given by (19) due to the presence of nonlinearities [30].

First machining centers with linear motor propulsion were built by Ingersoll Milling Machine Company, Rockford, IL, USA and LMT Consortium, Japan [22] in the mid 1990s. In machining centers built by Ingersoll, LSMs series LF manufactured by Anorad [4] have been installed. Table 4 shows specifications of the LMT96 machining center shown in Fig. 10 manufactured by LMT Consortium [22].

Mazak Corporation, Florence, KY, USA uses LSMs for the $x, y$ and $z$ axes in the F3-660L horizontal machining center, which is designed for automotive applications, especially for die-cast aluminum such as vehicle transmission casings [11]. With a rapid traverse of $120 \mathrm{~m} / \mathrm{min}$ in the $x$-axis and $50 \mathrm{~m} / \mathrm{min}$ on the $y$ and $z$ axes, the table is capable of accelerating at $0.5 \mathrm{~g}$ in all axes.

The cost of machining centers with linear motors is almost twice of that with ball lead screws.

Table 4. Specifications of machining center LMT96 manufactured by LMT consortium, Japan.

\begin{tabular}{|l|c|}
\hline Mass of machining center, $\mathrm{kg}$ & 16,000 \\
\hline Dimensions length $\times$ width $\times$ height, $\mathrm{m}$ & $4.4 \times 4.4 \times 2.9$ \\
\hline Stroke, $\mathrm{m}$ & \\
- $x$ axis & 0.8 \\
- $y$ axis & 0.5 \\
\hline$\quad z$ axis & 0.5 \\
\hline Maximum feed rate $v_{\text {max }}, \mathrm{m} / \mathrm{min}$ & \\
- $x$ axis & 80 \\
- $y$ axis & 80 \\
- $z$ axis & 80 \\
\hline Maximum acceleration $a_{\text {max }}$ & \\
- $x$ axis & $1.0 \mathrm{~g}$ \\
- $y$ axis & $2.0 \mathrm{~g}$ \\
- $z$ axis & $1.0 \mathrm{~g}$ \\
\hline Spindle & \\
- Diameter, mm & 65 \\
- Rated output power, kW & $15 / 22$ \\
- Rotational speed, rpm & 30,000 \\
\hline Tools & \\
- Number of tools & \\
- Tool selection & 12 \\
- Maximum diameter of tool, mm & 100 \\
- Maximum length of tool, mm & 250 \\
- Time required to change tool-to-tool & $1.5 \mathrm{~s}$ \\
- Time required to change chip-to-chip & $3.5 \mathrm{~s}$ \\
\hline
\end{tabular}

\subsection{Aircraft Machining}

Most wing ribs and floor spars on aircraft are made of stamped sheet metal cut to a contour [26]. Extrusion stock is then riveted to one or both faces to add strength. A small wing rib could be $50 \times 250 \times 1350 \mathrm{~mm}$ in dimension, while floor spars can be up to $0.9 \mathrm{~m}$ wide and more than $6 \mathrm{~m}$ in length. Since a typical commercial jetliner has around 100 wing ribs and another 100 floor spars, the time in labor, as well as the cumulative weight of the components, tends to add up [26].

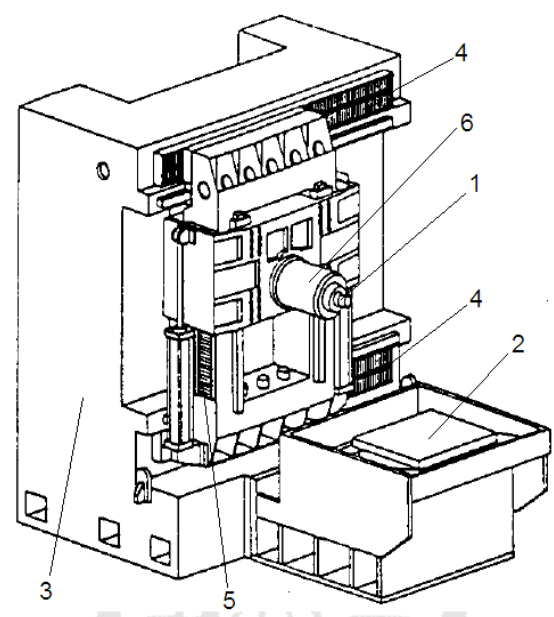

Fig. 10. Machining center LMT96 with Anorad LSMs manufactured by LMT Consortium, Japan. 1 . cutting tool, 2. pallet exchange system, 3 . column, 4. x-axis LSM, 5. z-axis LSM, 6 . spindle rotary motor.

Monolithic parts, i.e., structural components hogged out of single billets of metal, usually aluminum, can save time and cost in manufacturing. Making wing ribs, floor spars, fuselage frames, and other parts with pockets and honeycomb structures from single aluminum pieces would use about the same amount of material as sheet metal assembly. The real savings would be in the elimination of hundreds of fasteners, increased production speed, elimination of tooling, and the production of those tools [26]. The main problem has been how to machine these large parts with high speed, efficiency and repeatable accuracy.

The HyperMach program (Boeing, McDonnell Douglas, United Technologies Corporation, and US Air Force as primary partners) has solved this problem with the aid of LSMs. The HyperMach ${ }^{\mathrm{TM}}$ aerospace vertical profiler with Kollmorgen and Anorad LSMs can make contours at feed rates of over $100 \mathrm{~m} / \mathrm{min}$ accelerating as fast as $2 g$ [26]. Machine range is over $0.914 \mathrm{~m}$ in the $x$-axis, $1.5 \mathrm{~m}$ in the $y$ axis, and $0.75 \mathrm{~m}$ in the $z$-axis. This machine platform offers high-efficiency machining for both thin and thick plate processing of a wide variety of large aluminum structural components such as ribs, bulkheads, plate, frames, stringers, and spars to meet the demands of next generation aircraft parts. The $x$ and $y$ axes are driven by PM LSMs.

A high precision vertical grinding center for complete machining of a wide range of aerospace components such as nozzles, ball screws, landing gear flaps, etc., can only be 
designed using LSM technology and precision linear slides [26].

\section{Additive Manufacturing}

Additive manufacturing is a new paradigm for industrial manufacturing. Additive manufacturing techniques create 3D solid objects directly from a computer model using a 3D printing, depositing successive layers of material in different shapes only where required.

Dispensing fluids or coatings over complex geometries requires a motion system with multiple degrees of freedom to move either the printing head or the substrate with up to six degrees of freedom. Overall system accuracy and throughput are vitally important to creating complex structures with a commercially viable process. Linear positioning stages and linear gantries offer the best available accuracy, repeatability and long-term reliability [2].

\section{Surface Treatment and Finishing}

\subsection{Laser Scribing Systems}

Aircraft aluminum skin panels are usually scribed manually through templates prior to chemical milling. This costly process can be automated by the use of laser scribers and LSMs [12], [24]. An automatic laser maskant scriber with LSMs was built in 1993 for Boeing, Wichita, KS, US A [12]. In the etched machining process, the laser scribed metal surface (aircraft component parts) is coated with polymer material. The laser process is kept smoke free, and the scribed line is kept clean through the use of the smoke extraction hood installed on the optical laser wrist. The polymer is scribed to a desired pattern and then removed from the surface. The metal is then placed in an acid solution that etches out the exposed surfaces.

Two parallel LSMs, (series LF, Anorad [4]) produce the peak thrust up to $9 \mathrm{kN}$ at speed up to $5 \mathrm{~m} / \mathrm{s}$ [24]. LSMs rapidly and precisely position a huge gantry with the $\mathrm{CO} 2$ laser maskant scribing system. Two laser systems have been used: one for scribing and another for position feedback. The use of a laser interferometer for positioning feedback with LSM drive mechanisms results in high accuracy and repeatability.

The advantages of the LSM driven laser maskant scriber include mass, scrap and inventory reduction, noncontact design, no lubrication and adjustments, elimination of the stress channel, and minimizing back bending and repetitive motions. According to Boeing, this is the largest automatic laser scriber in the world ( $33 \mathrm{~m}$ long, $3 \mathrm{~m}$ wide, and $5.1 \mathrm{~m}$ tall) that can hold two Boeing 747 wings simultaneously, scribing one while positioning the other and scribe up to $2.54 \mathrm{~m} / \mathrm{s}$ or complete up to four skin panels in $1 \mathrm{~h} \mathrm{[24].}$
Le Creneau Industriel, Annecy le Vieux, France, is a manufacturer of 5 axis machining centers for routing and drilling aluminum and large-dimension composite components for the aircraft industry. The 5-axis UGV machine has overhead moving gantry, Coherent $100 \mathrm{~W}$ CO2 laser, and laser wrist [17]. The optical laser wrist is designed with a large $9 \mathrm{~m} \times 4.5 \mathrm{~m} \times 1.5 \mathrm{~m}$ work envelope moving gantry. It incorporates a Siemens Simodrive 840D CNC with $1 F N$ flux-switching LSMs to provide high accuracy with speeds up to $60 \mathrm{~m} / \mathrm{min}$ [17]. The curved component to be laser processed is placed on a 99-peg support fixture to form the precise $3 \mathrm{D}$ shape required. The complex pattern is scribed up to $30 \mathrm{~m} / \mathrm{min}$ with an accuracy of $\pm 0.025 \mathrm{~mm}$.

\subsection{Application of Flux-Switching PM Linear Motors}

Large gantry systems and machining centers require powerful linear motors, preferably with PM-free reaction rail. Siemens 1FN6 PM LSMs with a magnet-free reaction rail belong to the group of the so called flux-switching PM machines [19], [33], [40]. The armature system is air cooled, degree of protection IP23, class of insulation F, line voltage from 400 to $480 \mathrm{~V}$, rated thrust from 235 to $2110 \mathrm{~N}$, maximum velocity at rated thrust from 170 to $540 \mathrm{~m} / \mathrm{min}$, overload capacity 3.8 of the rated thrust, modular type construction [35]. These LSMs operate with Siemens Sinamics or Simodrive solid-state converters and external encoders. According to Siemens [35], these new LSMs produce thrust forces and velocities equivalent to competitive classical models for light-duty machine tool, machine accessory, and material handling applications.

The magnet-free reaction rail is easy to install and does not require the safety considerations of standard PM reaction rails. Without PMs, there is no problem with ferrous chips and other debris being attracted to these sections. Maintenance becomes a simple matter of installing a wiper or brush on the moving part of the slide.

The 1FN6 flux-switching LSM comprises an armature section that is equipped with coils and PMs as well as a nonmagnetic, toothed reaction rail section (Fig. 11). The key design innovation is an LSM in which PMs are integrated directly into the lamination of the armature core along with the individual windings for each phase. Both magnitudes and polarities of the linkage flux in the armature winding vary periodically along with the reaction rail movement. The magnetic flux between the armature core and steel reaction rail is controlled by switching the three-phase armature currents according to a designated algorithm [32]. The passive reaction rail consists of milled steel with poles (teeth) and is much simpler to manufacture.

$$
\tau_{2}=\frac{\tau_{1}}{1 \pm \frac{k}{m_{1}}}
$$




$$
P_{2}=P_{1} \frac{\tau_{1}}{\tau_{2}}
$$

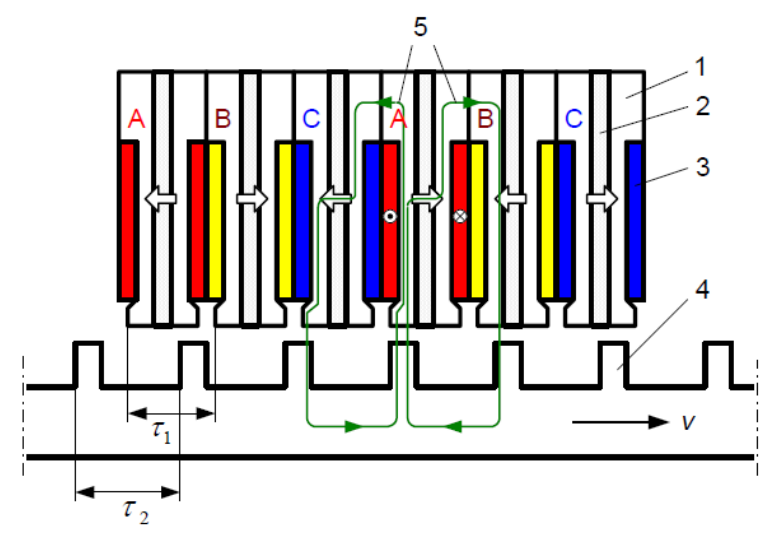

Fig. 11. Construction of flux-switching LSM with PM-free reaction rail. 1. laminated armature core, 2. PM, 3. armature coil (phase C), 4. toothed passive steel reaction rail, 5. linkage magnetic flux (phase $\mathrm{A}$ is on).

where $\tau_{1}, \tau_{2}$ are pole pitches of the armature and reaction rail, respectively, $P_{1}$ and $P_{2}$ are the numbers of the armature and reaction rail poles, respectively, and $k=1,2$, $3, \ldots$ is an integer. For example, if $\tau_{l}=42 \mathrm{~mm}, m_{l}=3$ and $k=1$, the reaction rail pole pitch $\tau_{2}=42 /[1 \pm$ $(1 / 6)]=36 \mathrm{~mm}$ or $50.4 \mathrm{~mm}$. Assuming $P_{1}=12$, the possible number of reaction rail poles is $P_{2}=12 \times$ $(42 / 36)=14$ or $\mathrm{P}_{2}=12 \times(42 / 50.4)=10$.

As far as the author is aware, the first paper on fluxswitching PM brushless rotary machines was published in 1955 [33]. There are numerous papers on the analysis of this type of machines, e.g., [5], [6], [19], [21], [40]. However, it is impossible to find a convincing analysis published so far on how flux-switching PM brushless motors compare to standard PM brushless motors in terms of thrust density, efficiency, and power factor. Some constructions of flux-switching PM LSMs have been patented, e.g., JP2002199679, FR2840124, GB2450465.

\section{Conclusion}

Although industry shows marginal interest in applications of linear electric motors to machining processes, linear motors show several advantages over ball screw mechanisms, i.e., higher linear speed, zero backlash, low life-cycle cost and low level of noise. On the other hand, linear electric motors are of lower force density and more expensive machines than linear actuators with ball screws and rotary electric motors. Nevertheless, linear electric motors are excellent electromechanical energy conversion devices for large machining centers being used for machining large parts, as for example, wing skin, landing gear flaps and nozzles, wing ribs and floor spars of commercial aircraft.

\section{Acknowledgements}

This article summarizes a Keynote Speech delivered by the author at the 9th Int. Symposium "Linear Drives for Industry Applications LDIA'2013", Hangzhou, China, July 7-10, 2013.

\section{References}

[1] AGS20000 Linear Motor Gantries, Aerotech, Inc., Pittsburgh, PA, USA, 2002, www.aerotechinc.com

[2] Additive Manufacturing, Aerotech, Inc., Pittsburgh, PA, USA 2013, http://www.aerotech.com/industries-andapplications/additive-manufacturing.aspx

[3] G.H. Amber, and P.S. Amber, Anatomy of Automation, Englewood Cliffs: Prentice-Hall, NJ, 1962.

[4] Anorad Linear Motors, information brochure, Anorad, Shirley, NY, USA, 2007, www.anorad.com

[5] L. Bart, J. Gysen, E. Ilhan, K.J. Meessen, J.J.H. Paulides and E.A. Lomonova, "Modeling of flux switching permanent magnet machines with Fourier analysis," IEEE Trans. on MAG, vol. 46, No. 6, pp. 1499-1502, 2010.

[6] A. Chen, R. Nilssen and A. Nysveen, "Analytical design of high- torque flux-switching permanent magnet machine by a simplified lumped parameter magnetic circuit," Int. Conf. on Electr. Machines ICEM'10, Rome, Italy, available on CD, 2010.

[7] S.U. Chung, H.J. Lee, D.K. Hong, J.Y. Lee, B.C. Woo and D.H.Koo, "Development of flux reversal linear synchronous motor for precision position control," Int. Journal of Precision Engineering and Manufacturing, vol. 12, No. 3, pp. 443-450, 2011.

[8] Compumotor Digiplan: Positioning Control Systems and Drives, Parker Hannifin Corporation, Rohnert Park, CA, USA, 2011.

[9] N. Corsi, R. Coleman and D. Piaget, "Status and new development of linear drives and subsystems," Keynote Address, Int. Symp. on Linear Drives for Ind. Appl. LDIA'07, Lille, France, available on CD, 2007.

[10] E.P. DeGarmo, J.T. Black and R.A. Kohser, Materials and Processes in Manufacturing, New York: Macmillan, 1988.

[11] B. Donahue, "The line on linear," Today's Machining World, pp. 16-20, June 2010.

[12] B. Eidelberg, "Linear motors drive advances in industrial laser applications," Industrial Laser Review, No. 1, pp. 15-18, 1995.

[13] J.F. Gieras, Linear Induction Drives, Oxford: Clarendon Press, UK, 1994

[14] J.F. Gieras, "Status of linear motors in the United States," Int. Symp. on Linear Drives for Ind. Appl. LDIA'03, Birmingham, UK, 2003.

[15] J.F. Gieras, "Linear electric motors in aircraft technology: an overview," Int. Symp. on Linear Drives for Ind. Appl. LDIA'09, Seoul, S. Korea, available on CD, 2009.

[16] J.F. Gieras, Z.J. Piech, B.Z. Tomczuk, Linear Synchronous Motors: Transportation and Automation Systems, 2nd ed., Boca Raton - London - New York: Taylor \& Francis, CRC Press, 2012. 
[17] G.J. Haas, Industrial Laser Solutions, No 11, pp. 17-19, 2003, www.industrial-laser.com

[18] G. Hagiz, My love affair with computers and CNC, 2007, http://numeryx.com

[19] E. Hoang, A.H.B. Ahmed and J. Lucidarme, "Switching-flux permanent magnet polyphase synchronous machines," 7th European Conf. on Power Electronics and Appl. EPE'97, Vol. 3, Trondheim, Norway, pp. 903-908, 1977.

[20] D. Howe and Z.Q. Zhu, "Status of linear permanent magnet and reluctance motor drives in Europe," 2nd Int. Symp. on Linear Drives for Ind. Appl. LDIA'98, Tokyo, Japan, pp. 1-8, 1998.

[21] E. Ilhan, B.L.J. Gysen, J.J.H. Paulides, and E.A. Lomonova, "Analytical hybrid model for flux switching permanent magnet machines," IEEE Trans. on MAG, vol. 46, No. 6, pp. 1762-1765, 2010.

[22] Y. Kakino, "Tools for high speed and high acceleration feed drive aystem of NC machine tools," 2nd Int. Symp. on Linear Drives for Ind. Appl. LDIA'98, Tokyo, Japan, 1998, pp. 1521.

[23] M. Karita, H. Nakagawa, and M. Maeda, "High thrust density linear motor and its applications," 1st Int. Symp. on Linear Drives for Ind. Appl. LDIA'95, Nagasaki, Japan, 1995, pp. 183-186.

[24] R. King, "Precision laser scribes aircraft skins, Design News, 1994, No. 5-9, pp. 66-67.

[25] Linear and Rotary Positioning Stages Engineering Reference, Parker Hannifin, Rohnert Park, CA, USA, 2005, www.parkermotion.com/engineeringcorner

[26] R. Mandel, "Linear motors drive aerospace machining to higher speeds," 2000, www.manufacturingcenter.com/dfx/archives/1100

[27] J. Moscrop, C. Cook and F. Naghdy, "Development and performance analysis of a single-axis linear motor test-bed," Australasian Universities Power Eng. Conf. AUPEC'01, Perth , Australia, pp. 607-612, 2001.

[28] Y. Muraguchi, M. Karita, H. Nakagawa, T. Shinya, and M. Maeda, "Method of measuring dynamic characteristics for linear servo motor and comparison of their performance," 2nd Int. Symp. on Linear Drives for Ind. Appl. LDIA'98, Tokyo, Japan, pp. 204-207, 1998.

[29] Northern Magnetics Linear Motors Technology, Normag (Baldor Electric Company), Santa Clarita, CA, USA, 1998.

[30] Z. Pandilov, "Analytical determination of the position loop gain for linear motor CNC machine tool," Journal AMME, vol. 26, No 2, pp. 171-174, 2008, www.journalamme.org

[31] PlatinumTM DDL Direct Drive Linear Motors, Kollmorgen, Radford, VA, USA, 1998, www.kollmorgen.com

[32] A. Presher, "New class of linear motors," Design News, November 16, 2009, www.designnews.com/article/388467

[33] S.E. Rauch, and L.J. Johnson, "Design principles of fluxswitch alternators," AIEE Trans., Part III, vol. 74, No. 12, pp. 1261-1269, 1955.

[34] B. Smith, "Going direct, " California Linear Drives, Carlsbad, CA, (USA) 2001, www.calinear.com

[35] Synchronous Linear Motor 1FN6: The Electrical Gear Rack, Siemens AG Industry Sector, Drive Technologies: Motion Control, Erlangen, Germany, 2008.

[36] V. Tergan, I. Andreev, and B. Liberman, B., Fundamentals of Industrial Automation, Moscow, Russia, Mir Publishers, 1986

[37] The Contactless Power Supply System of the Future, Wampfler AG, Weil am Rhein-Maerkt, Germany, 1998.

[38] Trilogy PM Linear Motors, Trilogy Systems Corp., Webster, TX, USA, 1999, www.trilogysystems.com
[39] H. Yamada, Handbook of Linear Motor Applications (in Japanese), Tokyo: Kogyo Chosaki Publishing Co., Japan, 1986.

[40] Z.Q., Zhu, Y. Pang, D. Howe, S. Iwasaki, R. Deodhar, and A. Pride, "Analysis of electromagnetic performance of of fluxswitching permanent magnet machines by non-linear adaptive lumped parameter magnetic circuit model," IEEE Trans. on MAG, Vol. 41, 2005, No. 11, pp. 4277-4287.

[41] Z.Q. Zhu, Z. Chen, D. Howe, and S. Iwasaki, "Electromagnetic modeling of a novel linear oscillating actuator," IEEE Trans on MAG, vol. 44, No 11, pp. 38553858, 2008.

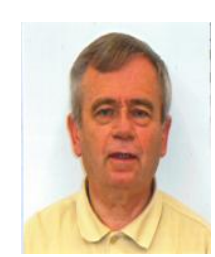

Prof. Jacek F. Gieras, FIEEE graduated in 1971 from the Technical University of Lodz, Poland, with distinction. He received his $\mathrm{PhD}$ degree in Electrical Engineering (Electrical Machines) in 1975 and Dr habil. degree (corresponding to DSc), also in Electrical Engineering, in 1980 from the University of Technology, Poznan, Poland. His research area is Electrical Machines, Drives and Electromagnetics. From 1971 to 1998 he pursued his academic career at several Universities worldwide including Poland (Technical University of Poznan and Academy of Technology and Agriculture Bydgoszcz), Canada (Queen's University, Kingston, Ontario), Jordan (Jordan University of Sciences and Technology, Irbid) and South Africa (University of Cape Town). He was also a Central Japan Railway Company Visiting Professor (Endowed Chair in Transportation Systems Engineering) at the University of Tokyo, Bunkyoku (1996), Guest Professor at Chungbuk National University, Cheongju, South Korea (1997), and Guest Professor at University of Rome La Sapienza, Italy (1994). In 1987 he was promoted to the rank of Full Professor (life title given by the President of the Republic of Poland). Since 1998 he has been affiliated with United Technologies Corporation, USA, most recently with UTC Aerospace Systems Applied Research. In 2007, he also became Faculty Member (Full Professor) of the University of Technology and Life Sciences in Bydgoszcz, Poland. Prof. Gieras authored and co-authored 11 books of international standing, over 250 scientific and technical papers and holds over 70 US patents and patent publications. The most important books are Linear Induction Motors, Oxford University Press, 1994, U.K., Permanent Magnet Motors Technology: Design and Applications, Marcel Dekker Inc., New York, 1996, 2nd edition 2002, 3rd edition 2010 (Taylor \& Francis), Linear Synchronous Motors: Transportation and Automation Systems, CRC Press LLC, Boca Raton, Florida, 1999, 2nd edition 2012, Axial Flux Permanent Magnet Brushless Machines, Springer-Kluwer Academic Publishers, Boston-Dordrecht-London, 2004, 2nd edition 2008, Noise of Polyphase Electric Motors, CRC Press - Taylor \& Francis, 2005, and Advancements in Electric Machines, Springer, Dordrecht-London-New York, 2008. 